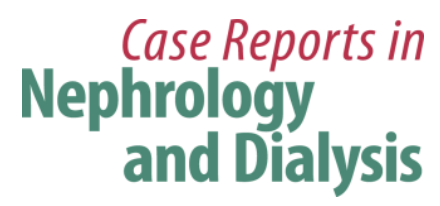

Case Rep Nephrol Dial 2017;7:34-42

DOI: $10.1159 / 000475492$

Published onIIne: IVlay 2, 2017

(C) 2017 The Author(s)
Published by S. Karger AG, Basel
www.karger.com/cnd

Karger

Open access

This article is licensed under the Creative Commons Attribution-NonCommercial 4.0 International License (CC BY-NC) (http://www.karger.com/Services/OpenAccessLicense). Usage and distribution for commercial purposes requires written permission.

\title{
Extracranial Aneurysms in 2 Patients with Autosomal Recessive Polycystic Kidney Disease
}

\author{
Daniel S. Elchediak ${ }^{a} \quad$ Anne Marie Cahill, e Emma E. Furth ${ }^{\text {c, e }}$ \\ Bernard S. Kaplan $^{\text {d, e }}$ Erum A. Hartung ${ }^{\text {d, e }}$ \\ ${ }^{a}$ Emory University, Atlanta, GA, USA; ${ }^{b}$ Department of Radiology, Children's Hospital of \\ Philadelphia, Philadelphia, PA, USA; ${ }^{C}$ Department of Pathology and Laboratory Medicine, \\ Hospital of the University of Pennsylvania, Philadelphia, PA, USA; ${ }^{\mathrm{d}}$ Division of Nephrology,

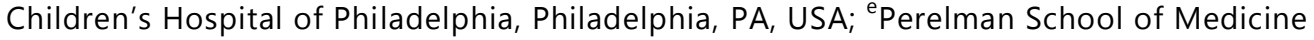 \\ at the University of Pennsylvania, Philadelphia, PA, USA
}

\section{Keywords}

Autosomal recessive polycystic kidney disease - Autosomal dominant polycystic kidney disease · Congenital hepatic fibrosis · Aneurysms · Arterial vascular malformations . Extracranial aneurysm $\cdot$ Portal hypertension

\begin{abstract}
Unlike autosomal dominant polycystic kidney disease (ADPKD), autosomal recessive polycystic kidney disease (ARPKD) is not generally known to be associated with vascular abnormalities. Only 4 cases of ARPKD patients with intracranial aneurysms have been reported previously. We present 2 ARPKD patients with extracranial vascular abnormalities: a young man with infrarenal aortic and iliac artery aneurysms complicated by dissection and a teenage girl with multiple splenic and gastric artery aneurysms and arterial vascular malformations. These cases raise the question of whether vascular integrity and development may be impaired in ARPKD, perhaps through molecular mechanisms overlapping with ADPKD. This possibility is supported by studies in mice that show ARPKD gene expression in the walls of large blood vessels.

(C) 2017 The Author(s)

Published by S. Karger AG, Basel
\end{abstract}




\section{Case Reports in Nephrology and Dialysis}

\section{Introduction}

Clinical manifestations of autosomal recessive polycystic kidney disease (ARPKD) include enlarged kidneys with innumerable collecting duct cysts, progressive chronic kidney disease (CKD), and liver disease with dilated intrahepatic bile ducts, congenital hepatic fibrosis (CHF), and portal hypertension [1]. In contrast to autosomal dominant polycystic kidney disease (ADPKD), in which intracranial aneurysms are reported in 5-10\% of patients [2-4], there is no strong association of vascular abnormalities with ARPKD. To date, there have been 4 reported cases of ARPKD patients with intracranial aneurysms [5-8]. To our knowledge, there have been no prior reports of ARPKD patients with extracranial aneurysms. Here, we describe 2 ARPKD patients who presented with unusual extracranial vascular abnormalities.

\section{Patient 1}

A 36-year-old male with ARPKD, stage 4 CKD, Caroli syndrome, CHF, and portal hypertension presented with 2 weeks of intermittent, cramping mid-lower abdominal pain radiating to the bilateral flanks. His past medical history was notable for hypersplenism with thrombocytopenia and esophageal varices without bleeding, previously treated with banding for primary prophylaxis. He had hepatocellular carcinoma at age 24 years and underwent hepatic wedge resection. He had no significant history of systemic hypertension.

Initial exam revealed a blood pressure of $135 / 77 \mathrm{~mm} \mathrm{Hg}$ with normal heart rate. He was not in acute distress. He had splenomegaly, minimal lower abdominal tenderness, hypoactive bowel sounds, and no abdominal bruits. He had no edema, normal capillary refill, and normal femoral and pedal pulses. Laboratory studies showed normal hemoglobin, platelets $90,000 / \mu \mathrm{L}$, serum creatinine $2.3 \mathrm{mg} / \mathrm{dL}$, INR 1.3, normal liver enzymes, total bilirubin 1.5 $\mathrm{mg} / \mathrm{dL}$, and serum albumin $3.1 \mathrm{~g} / \mathrm{dL}$.

Noncontrast abdominal computed tomography (CT) showed stranding along the infrarenal aorta and hypodensity in the left common iliac artery, suspicious for thrombus. Aorto-iliac duplex study revealed a $3.2-\mathrm{cm}$ fusiform infrarenal abdominal aortic aneurysm (AAA) and 1.9-cm aneurysms of the bilateral common iliac arteries, with possible dissection of the right common iliac artery. CT angiogram confirmed fusiform dilation of the infrarenal abdominal aorta ( $3.1 \mathrm{~cm}$ in diameter), with complex dissection extending from the level of the second lumbar vertebra to the right common iliac artery (Fig. 1). There was also fusiform dilation of the bilateral common iliac arteries $(1.9 \mathrm{~cm}$ in diameter) and of the celiac artery $(1.2 \mathrm{~cm}$ in diameter), with linear hypodensity in the celiac artery that was concerning for dissection.

He received anticoagulation with a heparin infusion followed by transition to oral warfarin and was started on oral propranolol for primary prophylaxis against esophageal variceal bleeding.

\section{Patient 2}

A 17-year-old female with ARPKD, stage $3 \mathrm{CKD}$, CHF, and severe portal hypertension with a history of multiple esophageal variceal bleeds (with portocaval shunt placement at age 3 years and multiple prior sclerotherapy treatments) presented with massive upper 


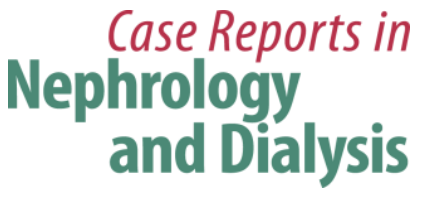

Case Rep Nephrol Dial 2017;7:34-42

DOI: $10.1159 / 000475492$

C 2017 The Author(s). Published by S. Karger AG, Basel www.karger.com/cnd

Elchediak et al.: Extracranial Aneurysms in 2 Patients with Autosomal Recessive Polycystic Kidney Disease

gastrointestinal (GI) tract bleeding with abdominal pain, hematemesis, and grossly bloody stool. She was tachycardic and hypotensive to $80 / 40 \mathrm{~mm} \mathrm{Hg}$. Gastric lavage showed gross blood. Laboratory studies showed hemoglobin $9.3 \mathrm{~g} / \mathrm{dL}$, platelets $75,000 / \mu \mathrm{L}$, serum potassium $5.5 \mathrm{mmol} / \mathrm{L}$, serum creatinine $1.3 \mathrm{mg} / \mathrm{dL}$, INR 1.6, and serum albumin concentration 1.8 $\mathrm{g} / \mathrm{dL}$. She had significant blood loss requiring numerous transfusions of packed red cells, platelets, plasma, and cryoprecipitate. Additional supportive therapy included octreotide infusion, pantoprazole, ranitidine, vitamin $\mathrm{K}$, vasopressors, intubation, and sedation.

Emergency endoscopy could not localize the source of bleeding due to a large amount of blood in the stomach. Emergency celiac angiography showed multiple aneurysms involving the celiac trunk, including multiple short gastric arteries, the splenic artery and its branches, and the left gastric artery (Fig. $2 \mathrm{a}-\mathrm{c}$ ). She developed massive hemorrhage from the left gastric artery during the procedure, and coil embolization was performed with cessation of bleeding. Recurrent GI bleeding 2 days later necessitated exploratory laparotomy and oversewing of the bleeding vessel. Over the following 2 years, she had recurrent episodes of GI hemorrhage. At age 19 years, she presented with massive GI bleeding refractory to medical and endoscopic therapies. She underwent emergent subtotal gastrectomy, splenectomy, and transverse colectomy but died the following day. Gastric pathology revealed multiple large submucosal arterial vascular malformations (up to $3.5 \mathrm{~cm}$ in diameter; Fig. 2d, e), some with ulceration of the overlying mucosa (Dieulafoy-like lesions).

\section{Discussion}

There have been 4 prior reports of intracranial aneurysms in ARPKD patients [5-8], but to our knowledge, these are the first reported cases of ARPKD patients with extracranial vascular abnormalities. Patient 1 presented in his 4th decade with an AAA and common iliac artery aneurysms with dissection. Patient 2 presented as a teenager with multiple aneurysms and arterial vascular malformations arising from branches of the celiac artery, including the splenic artery and its branches, and the gastric arteries. Pathology showed large submucosal arterial vascular malformations, suggestive of a developmental vascular defect.

It is unlikely that these vascular abnormalities represent a simple coincidence with ARPKD. AAA and iliac artery aneurysms are the first and second most common intraabdominal arterial aneurysms in the general population [9]. However, AAA is exceedingly rare in younger age groups; in a population-based study of over 6,000 individuals aged 2584 years, no one aged less than 48 years had AAA [10]. Patient 1 had no other risk factors for AAA, such as hypertension, smoking, or hypercholesterolemia [11]. However, CKD is also a risk factor for AAA [12] and may have been a predisposing factor in this patient.

Splenic artery aneurysms (SAA) are the third most common intra-abdominal arterial aneurysms [9] but are rare, with an estimated population prevalence of $0.78 \%$ [13]. However, SAA is much more common in patients with portal hypertension, with a prevalence as high as $8.8 \%$ in patients with cirrhotic portal hypertension [14]. SAA is also more common in females than in males [9]. Patient 2 had both of these risk factors. However, aneurysms of the gastric arteries are much rarer, representing only about $2 \%$ of true splanchnic artery aneurysms [15]. In addition, the gastric histopathology in patient 2 was more consistent with a primary developmental arterial vascular defect rather than a secondary aneurysmal weakening of the vessel walls.

It is possible that these patients had a coexisting primary vascular disorder, such as fibromuscular dysplasia, which has been associated with aneurysms and dissection in aortic, 


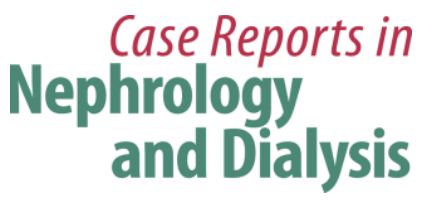

Case Rep Nephrol Dial 2017;7:34-42

DOI: $10.1159 / 000475492$

c 2017 The Author(s). Published by S. Karger AG, Basel www.karger.com/cnd

Elchediak et al.: Extracranial Aneurysms in 2 Patients with Autosomal Recessive Polycystic Kidney Disease

iliac, and celiac artery distributions [16]. Although we cannot disprove this possibility, we note that any characteristic histopathologic findings of fibromuscular dysplasia, such as medial fibroplasia, medial hyperplasia, intimal fibroplasia, and perimedial dysplasia [17], were absent in patient 2 .

Given our patients' other risk factors for intra-abdominal aneurysms, including CKD and portal hypertension [14, 18], it is possible that the aneurysms resulted from nonspecific secondary effects of other pathological factors rather than a direct association with ARPKD. However, these cases, along with the prior reports of intracranial aneurysms in ARPKD patients [5-8], raise the question of whether there could be disease-specific effects of ARPKD on vascular integrity or development. The association of ADPKD with intracranial aneurysms is well established [2-4], and since the pathways involved in ARPKD and ADPKD are linked, it is possible that there is a previously underrecognized overlap in the vascular phenotype.

ARPKD is caused by mutations in PKHD1 (6p21.1-p12) [19, 20], a large gene whose protein product, fibrocystin/polyductin (FPC), is a single membrane-spanning protein that is expressed most highly in tubular epithelia of the kidney, bile ducts, and pancreas [20,21]. Mouse studies have also shown strong gene expression in the muscular wall of large blood vessels, including the thoracic and abdominal aorta [22].

ADPKD is caused by mutations in 1 of 2 genes, PKD1 (16p13.3), accounting for $\sim 85 \%$ of patients [23], or PKD2 (4q21). The PKD1 product, polycystin-1, is a large integral membrane protein, and the $P K D 2$ product, polycystin-2, is a calcium-transporting channel in the transient receptor potential (TRP) family [24]. Polycystin-1 is widely expressed in adult tissues, particularly in renal tubular epithelia [25]. Mouse studies have also shown high levels of Pkd1 expression in the heart, aorta, intracranial arteries, and other major blood vessels. Polycystins-1 and -2 interact to form a complex [26] that localizes to the primary cilium [27], an organelle with essential signaling and sensory roles in numerous mammalian cell types, including renal tubules [28]. The ARPKD protein, FPC, also interacts with polycystin-2 and regulates its expression and function [29-31]. Thus, common signaling pathways appear to underlie the pathophysiology of ARPKD and ADPKD.

ADPKD is strongly associated with vascular abnormalities, particularly intracranial aneurysms, which occur in 5-10\% of patients [2-4]. Other vascular abnormalities have also been described in ADPKD, including intracranial dolichoectasia [32, 33], ascending aortic aneurysms [34], and dissections of the coronary [35, 36] and vertebral [37] arteries. It has also been suggested that ADPKD patients are at higher risk for AAA [38-41], although a systematic study found no increased risk of AAA in ADPKD patients compared to healthy family members [42].

As reviewed recently by Perrone et al. [43], there is evidence to suggest that polycystins are involved in maintaining vascular integrity [44]. ADPKD has been associated with endothelial dysfunction and defects in angiogenesis [45]. Possible mechanisms for these defects include abnormal mechanosensation by vascular endothelial primary cilia [46], abnormal endothelial cell migration [47], or dysregulation of VEGF pathways [48] or TGF- $\beta$ signaling [49].

Data from animal models also suggest a role for FPC in maintaining vascular integrity. Abnormal microvascular structure has been described in the PCK rat model of ARPKD [50]. In this model, endothelial dysfunction occurs even before the onset of hypertension or CKD, suggesting a primary effect of ARPKD [51].

These 2 patients, along with the biological evidence that polycystins and FPC have a role in maintaining vascular integrity, highlight the need for further studies to elucidate whether 
ARPKD patients may be at higher risk for vascular complications. In the meantime, increased vigilance for these serious complications seems warranted in ARPKD patients.

\section{Acknowledgements}

The authors are grateful to patient 1 and his mother for providing updated information. We are also grateful to Colleen Zak, RN, for encouraging us to report these cases and for everything that she has done to further the investigation of ARPKD.

\section{Statement of Ethics}

Informed consent was obtained as appropriate. The Children's Hospital of Philadelphia Institutional Review Board has determined that this case report does not meet the definition of human subjects research and does not require review.

\section{Disclosure Statement}

The authors have no conflicts of interest to declare.

\section{Funding Sources}

There are no funding sources to report.

\section{References}

1 Hartung EA, Guay-Woodford LM: Autosomal recessive polycystic kidney disease: a hepatorenal fibrocystic disorder with pleiotropic effects. Pediatrics 2014;134:e833-e845.

-2 Graf S, Schischma A, Eberhardt KE, Istel R, Stiasny B, Schulze BD: Intracranial aneurysms and dolichoectasia in autosomal dominant polycystic kidney disease. Nephrol Dial Transplant 2002;17:819-823.

-3 Chapman AB, Rubinstein D, Hughes R, et al: Intracranial aneurysms in autosomal dominant polycystic kidney disease. N Engl J Med 1992;327:916-920.

-4 Huston J, Torres VE, Sulivan PP, Offord KP, Wiebers DO: Value of magnetic resonance angiography for the detection of intracranial aneurysms in autosomal dominant polycystic kidney disease. J Am Soc Nephrol 1993;3:1871-1877.

-5 Chalhoub V, Abi-Rafeh L, Hachem K, Ayoub E, Yazbeck P: Intracranial aneurysm and recessive polycystic kidney disease: the third reported case. JAMA Neurol 2013;70:114-116.

-6 Lilova MI, Petkov DL: Intracranial aneurysms in a child with autosomal recessive polycystic kidney disease. Pediatr Nephrol 2001;16:1030-1032.

7 Neumann HP, Krumme B, van Velthoven V, Orszagh M, Zerres K: Multiple intracranial aneurysms in a patient with autosomal recessive polycystic kidney disease. Nephrol Dial Transplant 1999;14:936-939.

8 De Blasi R, Lasjaunias P, Rodesch G, Alvarez H: Endovascular treatment of a ruptured intracranial arterial aneurysm in a 12-year-old child with recessive polycystic kidney disease. Interv Neuroradiol 1997;3:333-336.

9 Al-Habbal Y, Christophi C, Muralidharan V: Aneurysms of the splenic artery - a review. Surgeon 2010;8:223-231.

10 Singh K, Bønaa KH, Jacobsen BK, Bjørk L, Solberg S: Prevalence of and risk factors for abdominal aortic aneurysms in a population-based study: the Tromsø Study. Am J Epidemiol 2001;154:236-244. 


\section{Case Reports in Nephrology and Dialysis}

\begin{tabular}{l|l}
\hline DOI: $10.1159 / 000475492$ & $\begin{array}{l}\text { ( ) } 2017 \text { The Author(s). Published by S. Karger AG, Basel } \\
\text { www.karger.com/cnd }\end{array}$ \\
\hline
\end{tabular}

Elchediak et al.: Extracranial Aneurysms in 2 Patients with Autosomal Recessive Polycystic Kidney Disease

11 Forsdahl SH, Singh K, Solberg S, Jacobsen BK: Risk factors for abdominal aortic aneurysms: a 7-year prospective study: the Tromso Study, 1994-2001. Circulation 2009;119:2202-2208.

$\checkmark 12$ Chun KC, Teng KY, Chavez LA, et al: Risk factors associated with the diagnosis of abdominal aortic aneurysm in patients screened at a regional Veterans Affairs health care system. Ann Vasc Surg 2014;28:87-92.

13 Stanley JC, Fry WJ: Pathogenesis and clinical significance of splenic artery aneurysms. Surgery 1974;76:898-909.

-14 Puttini M, Aseni P, Brambilla G, Belli L: Splenic artery aneurysms in portal hypertension. J Cardiovasc Surg (Torino) 1982;23:490-493.

15 Tétreau R, Beji H, Henry L, Valette P-J, Pilleul F: Arterial splanchnic aneurysms: presentation, treatment and outcome in 112 patients. Diagn Interv Imaging 2016;97:81-90.

-16 Bolen MA, Brinza E, Renapurkar RD, Kim ESH, Gornik HL: Screening CT angiography of the aorta, visceral branch vessels, and pelvic arteries in fibromuscular dysplasia. JACC Cardiovasc Imaging 2016, DOI: 10.1016/j.jcmg.2016.04.010.

17 Stanley JC, Gewertz BL, Bove EL, Sottiurai V, Fry WJ: Arterial fibrodysplasia. Histopathologic character and current etiologic concepts. Arch Surg 1975;110:561-566.

18 Ueda J, Takahashi S, Furukawa T, Araki Y: Portal hypertension with intra- and extrasplenic arterial aneurysms and large venous varices. Cardiovasc Intervent Radiol 1995;18:243-246.

19 Onuchic LF, Furu L, Nagasawa Y, et al: PKHD1, the polycystic kidney and hepatic disease 1 gene, encodes a novel large protein containing multiple immunoglobulin-like plexin-transcription-factor domains and parallel beta-helix 1 repeats. Am J Hum Genet 2002;70:1305-1317.

Ward CJ, Hogan MC, Rossetti S, et al: The gene mutated in autosomal recessive polycystic kidney disease encodes a large, receptor-like protein. Nat Genet 2002;30:259-269. Menezes LFC, Cai Y, Nagasawa Y, et al: Polyductin, the PKHD1 gene product, comprises isoforms expressed in plasma membrane, primary cilium, and cytoplasm. Kidney Int 2004;66:1345-1355. Nagasawa Y, Matthiesen S, Onuchic LF, et al: Identification and characterization of Pkhd1, the mouse orthologue of the human ARPKD gene. J Am Soc Nephrol 2002;13:2246-2258. Rossetti S, Consugar MB, Chapman AB, et al: Comprehensive molecular diagnostics in autosomal dominant polycystic kidney disease. J Am Soc Nephrol 2007;18:2143-2160. Harris PC, Torres VE: Polycystic kidney disease. Annu Rev Med 2009;60:321-337. epithelial cells in fetal, adult, and polycystic kidney. Proc Natl Acad Sci USA 1996;93:1524-1528. F, Germino F], Cai Y, Zhang X, Somlo S, Germin coiled-coil domain. Nat Genet 1997;16:179-183.

Yoder BK, Hou X, Guay-Woodford LM: The polycystic kidney disease proteins, polycystin-1, polycystin2, polaris, and cystin, are co-localized in renal cilia. J Am Soc Nephrol 2002;13:2508-2516.

-28 Yoder BK: Role of primary cilia in the pathogenesis of polycystic kidney disease. J Am Soc Nephrol 2007;18:1381-1388.

29 Kim I, Li C, Liang D, et al: Polycystin-2 expression is regulated by a PC2-binding domain in the intracellular portion of fibrocystin. J Biol Chem 2008;283:31559-31566.

-30 Kim I, Fu Y, Hui K, et al: Fibrocystin/polyductin modulates renal tubular formation by regulating polycystin-2 expression and function. J Am Soc Nephrol 2008;19:455-468. Wang S, Zhang J, Nauli SM, et al: Fibrocystin/polyductin, found in the same protein complex with polycystin-2, regulates calcium responses in kidney epithelia. Mol Cell Biol 2007;27:3241-3252. Graf S, Schischma A, Eberhardt KE, Istel R, Stiasny B, Schulze BD: Intracranial aneurysms and dolichoectasia in autosomal dominant polycystic kidney disease. Nephrol Dial Transplant 2002;17:819-823.

-33 Schievink WI, Torres VE, Wiebers DO, Huston J: Intracranial arterial dolichoectasia in autosomal dominant polycystic kidney disease. J Am Soc Nephrol 1997;8:1298-1303.

-34 Kim J, Kim SM, Lee SY, et al: A case of severe aortic valve regurgitation caused by an ascending aortic aneurysm in a young patient with autosomal dominant polycystic kidney disease and normal renal function. Korean Circ J 2012;42:136-139. Afari ME, Quddus A, Bhattarai M, John AR, Broderick RJ: Spontaneous coronary dissection in polycystic kidney disease. R I Med J 2013;96:44-45.

-36 Lee C-C, Fang C-Y, Huang C-C, Ng S-H, Yip H-K, Ko S-F: Computed tomography angiographic demonstration of an unexpected left main coronary artery dissection in a patient with polycystic kidney disease. J Thorac Imaging 2011;26:W4-W6.

-37 Larranaga J, Rutecki GW, Whittier FC: Spontaneous vertebral artery dissection as a complication of autosomal dominant polycystic kidney disease. Am J Kidney Dis 1995;25:70-74.

-38 Seshadri A, Byrne C, Kramer A, Bartlett ST, Sarkar R: Revascularization and rescue of a failed kidney transplant in a case of autosomal dominant polycystic kidney disease. J Vasc Surg 2012;55:1766-1768.

39 Inoguchi H, Komori K, Maehara Y: Surgical management of abdominal aortic aneurysm associated with polycystic kidney disease: report of two cases. Surg Today 2008;38:253-257. 
-40 Kato A, Takita T, Furuhashi M, Maruyama Y, Hishida A: Abdominal aortic aneurysms in hemodialysis patients with autosomal dominant polycystic kidney disease. Nephron 2001;88:185-186.

-41 Takagi H, Umemoto T: Abdominal aortic aneurysm and autosomal-dominant polycystic kidney disease. Kidney Int 2005;67:376.

-42 Torra R, Nicolau C, Badenas C, et al: Abdominal aortic aneurysms and autosomal dominant polycystic kidney disease. J Am Soc Nephrol 1996;7:2483-2486.

-43 Perrone RD, Malek AM, Watnick T: Vascular complications in autosomal dominant polycystic kidney disease. Nat Rev Nephrol 2015, DOI: 10.1038/nrneph.2015.128.

-44 Kim K, Drummond I, Ibraghimov-Beskrovnaya 0, Klinger K, Arnaout MA: Polycystin 1 is required for the structural integrity of blood vessels. Proc Natl Acad Sci USA 2000;97:1731-1736.

-45 Fick-Brosnahan GM: Endothelial dysfunction and angiogenesis in autosomal dominant polycystic kidney disease. Curr Hypertens Rev 2013;9:32-36.

-46 Mohieldin AM, Zubayer HSM, Al Omran AJ, et al: Vascular endothelial primary cilia: mechanosensation and hypertension. Curr Hypertens Rev 2016;12:57-67.

47 Outeda P, Huso DL, Fisher SA, et al: Polycystin signaling is required for directed endothelial cell migration and lymphatic development. Cell Rep 2014;7:634-644.

-48 Huang JL, Woolf AS, Long DA: Angiogenesis and autosomal dominant polycystic kidney disease. Pediatr Nephrol 2013;28:1749-1755.

49 Liu D, Wang CJ, Judge DP, et al: A Pkd1-Fbn1 genetic interaction implicates TGF- $\beta$ signaling in the pathogenesis of vascular complications in autosomal dominant polycystic kidney disease. J Am Soc Nephrol 2014;25:81-91.

50 Xu R, Franchi F, Miller B, et al: Polycystic kidneys have decreased vascular density: a micro-CT study. Microcirculation 2013;20:183-189.

51 Peterson KM, Franchi F, Loeffler DL, et al: Endothelial dysfunction occurs prior to clinical evidence of polycystic kidney disease. Am J Nephrol 2013;38:233-240. 


\section{Case Reports in Nephrology and Dialysis}

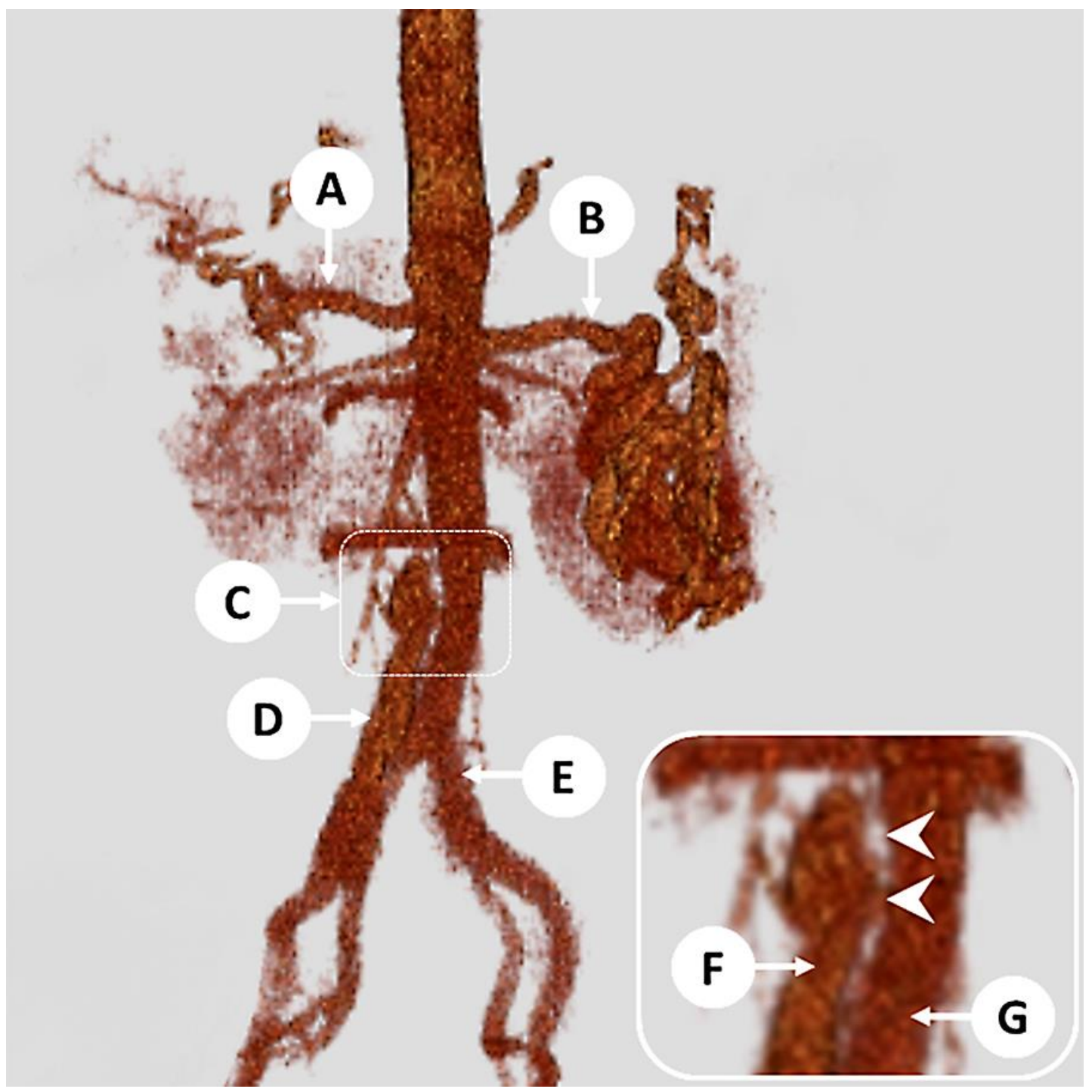

Fig. 1. Patient 1: 3-D reconstruction images of the aorta from the CT angiogram, demonstrating an abdominal aortic aneurysm with complex dissection extending into the right common iliac artery. A, common hepatic artery; B, splenic artery (tortuous); C, top of the aortic aneurysm and dissection (magnified in inset); D, false lumen extending into the right common iliac artery; $\mathrm{E}$, true lumen extending into the left common iliac artery; F, false lumen of the aorta; G, true lumen of the aorta. Inset Arrowheads indicate dissection flap in the aorta. 


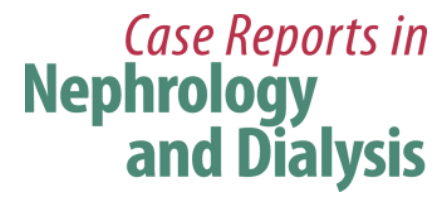

Case Rep Nephrol Dial 2017;7:34-42 DOI: $10.1159 / 000475492$

(C) 2017 The Author(s). Published by S. Karger AG, Basel www.karger.com/cnd

Elchediak et al.: Extracranial Aneurysms in 2 Patients with Autosomal Recessive Polycystic Kidney Disease

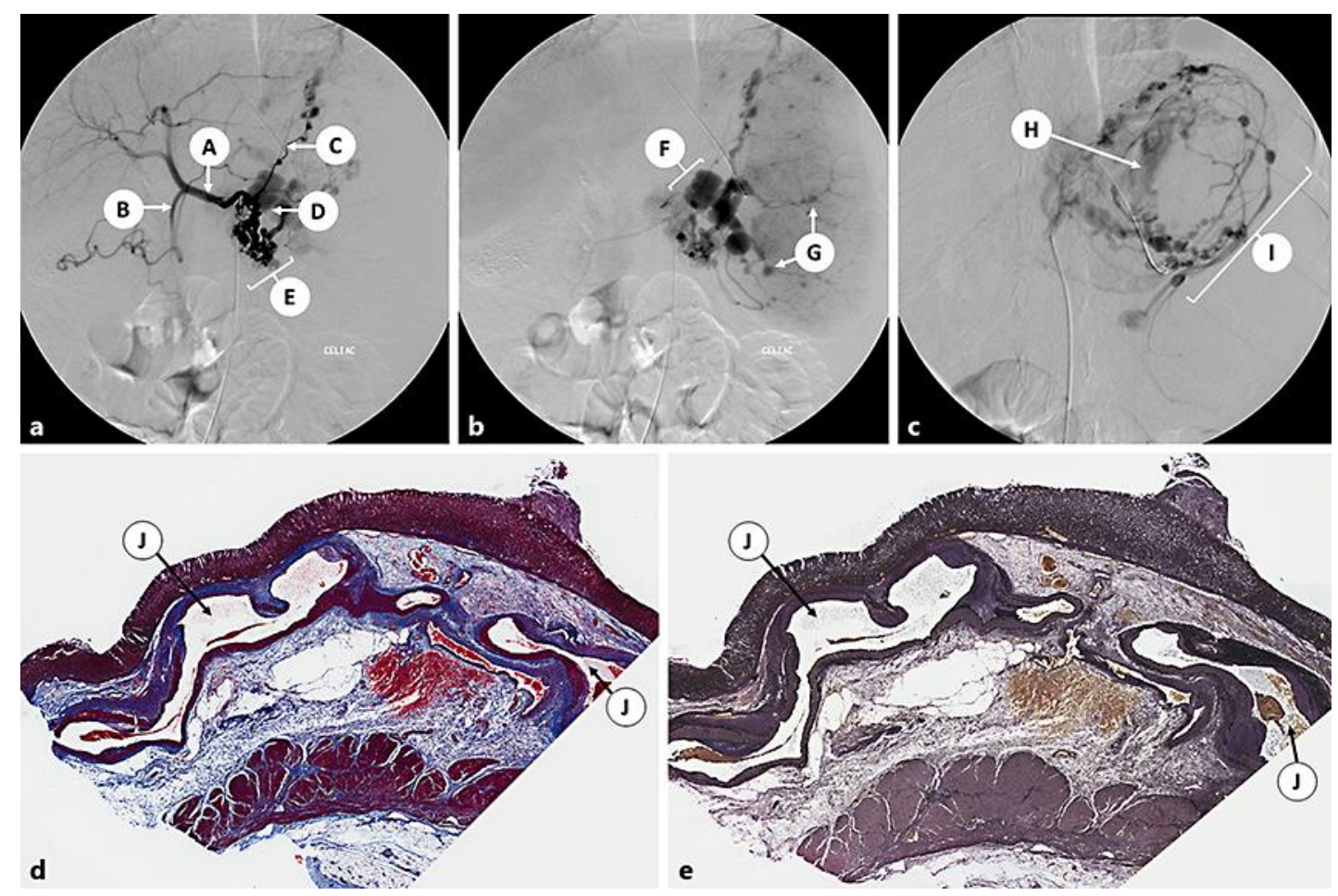

Fig. 2. Patient 2: Celiac angiography (a-c) and stomach pathology (d, e). a-c Celiac angiography demonstrates multiple aneurysms including multiple short gastric arteries, the splenic artery and its branches, and the left gastric artery. A, common hepatic artery; B, gastroduodenal artery; C, left gastric artery with multiple aneurysms; D, absent proximal splenic artery, occluded at origin; E, multiple aneurysms in presumed short gastric arteries; F, collaterals reconstituting distally into markedly deformed aneurysmal splenic artery stump; G, multiple intrasplenic aneurysms; H, active extravasation from the left gastric artery; I, multiple intragastric arterial aneurysms. d Stomach, trichrome stain. e Stomach, elastic stain. J, large submucosal arterial vascular malformations. 